Purdue University Purdue e-Pubs

1998

\title{
Unsteady-State Analysis of the Compression Cycle of a Hermetic Reciprocating Compressor
}

\author{
A. Cavallini \\ Universita di Padova \\ D. Del Col \\ Universita di Padova \\ L. Doretti \\ Universita di Padova \\ L. Rossetto \\ Universita di Padova \\ G. A. Longo \\ Universita di Padova \\ See next page for additional authors
}

Follow this and additional works at: https://docs.lib.purdue.edu/icec

Cavallini, A.; Col, D. Del; Doretti, L.; Rossetto, L.; Longo, G. A.; Pinto, A. D.; and Zannerio, A., "Unsteady-State Analysis of the Compression Cycle of a Hermetic Reciprocating Compressor" (1998). International Compressor Engineering Conference. Paper 1353. https://docs.lib.purdue.edu/icec/1353

This document has been made available through Purdue e-Pubs, a service of the Purdue University Libraries. Please contact epubs@purdue.edu for additional information.

Complete proceedings may be acquired in print and on CD-ROM directly from the Ray W. Herrick Laboratories at https://engineering.purdue.edu/ Herrick/Events/orderlit.html 
Authors

A. Cavallini, D. Del Col, L. Doretti, L. Rossetto, G. A. Longo, A. D. Pinto, and A. Zannerio 


\title{
UNSTEADY-STATE ANALYSIS OF THE COMPRESSION CYCLE OF A HERMETIC RECIPROCATING COMPRESSOR
}

\author{
A. Cavallini, D. Del Col, L. Doretti, L. Rossetto \\ Dipartimento di Fisica Tecnica - Università di Padova \\ Via Venezia 1, I-35131 Padova - ITALY \\ G.A. Longo \\ Dipartimento di Tecnica e Gestione dei Sistemi Industriali - Università di Padova \\ Viale X Giugno 22, I-36100 Vicenza - ITALY \\ A.D. Pinto, A. Zannerio \\ Electrolux Compressors \\ Piazzetta del Portello 2, I-33170 Pordenone - ITALY
}

\begin{abstract}
In this work a previous steady-state model [1] of a hermetic reciprocating compressor has been improved using an unsteady-state analysis of the compression cycle which allows a direct computation of the heat, work and mass flow rates. The new model requires the geometry of the machine, refrigerant inlet temperature and pressure, vapour discharge pressure, electric and mechanical efficiencies as input data. The output results include refrigerant outlet temperature, the mean temperatures of the main parts of the compressor, heat, work and mass flow rates and the behaviour of each characteristic parameter during the compression cycle.

The results of the simulation have been compared against experimental measurements carried out on two commercial units operating with R600a and R134a respectively.
\end{abstract}

\section{INTRODUCTION}

At the 1996 Purdue International Compressor Engineering Conference, the authors presented a steady-state thermal analysis [1] of a hermetic reciprocating compressor based on a politropic approach which required experimental investigation to determine the characteristic politropic index and volumetric efficiency of the compression process. In this work the above model has been improved using an unsteady-state analysis of the compression cycle based on the first law of thermodynamics applied to the refrigerant vapour during the process. This approach allows a direct computation of heat and work flow rates exchanged during the compression cycle together with the mass flow rate processed. The model requires the geometry of the machine, the refrigerant inlet ternperature and pressure, the surroundings temperature, vapour discharge pressure, electric and mechanical efficiencies as input data. The output results include refrigerant outlet temperature, the temperatures of the main parts of the compressor, heat, work and mass flow rates and the behaviour of each characteristic parameter (temperature, pressure, heat and work flow rates, leakage mass flow rate) during the compression cycle.

The model has been compared against the experimental measurements carried out on two different commercial compressors, one working with R134a and the other with R600a, instrumented with thermocouples and inserted into a calorimetry rig. The operative conditions tested range from an evaporation temperature $-35^{\circ} \mathrm{C}$ to $-10^{\circ} \mathrm{C}$. This comparison shows the model's fair ability in reproducing the machines investigated both in temperature distribution and heat, work and mass flow rates.

\section{THEORETICAL MODEL}

The basic assumption of the previous model [1] was to consider the refrigerant flow through the compressor as a one-dimensional steady-state flow. In this way, for each component and for the overall system, it was possible to 
establish a steady-state thermal balance to evaluate temperatures and heat and work flow rates. The main irreversibilities inside the compressor (electric energy conversion losses, friction losses) were taken into account by suitable electric and mechanical efficiencies, while the refrigerant mass flow rate was determined by assuming a suitable value for the volumetric efficiency. The compression process was simulated by a polytropic equation with an exponent $\mathrm{n}$ between $\mathrm{k}$ (adiabatic operation) and 1 (isotherm operation) to compute the operative conditions at the outlet of the cylinder and the heat and work flow rates exchanged. The electric, mechanical and volumetric efficiencies and the polytropic exponent $n$ were derived from experimental measurements.

In the present work, the politropic approach has been substituted by an unsteady-state analysis of the compression cycle. The first law of thermodynamics has been applied to the refrigerant inside the cylinder to determine its temperature behaviour through the compression process, as suggested by Todescat et al. 1992 [2], in the form:

$$
\left.\mathrm{dT} / \mathrm{d} \tau=\left[1 / \mathrm{M}(\tau) \mathrm{c}_{\mathrm{v}}\right)\right]\left\{\mathrm{q}(\tau)+\mathrm{m}_{\mathrm{s}}(\tau)\left[\mathrm{h}_{\mathrm{s}}-\mathrm{h}(\tau)\right]-\mathrm{T}(\tau)(\partial \mathrm{p} / \partial \mathrm{T})_{\mathrm{v}}\left[\mathrm{dV} / \mathrm{d} \tau-\mathrm{v}(\tau)\left[\mathrm{m}_{\mathrm{s}}(\tau)-\mathrm{m}_{\mathrm{l}}(\tau)-\mathrm{m}_{\mathrm{d}}(\tau)\right]\right]\right\}
$$

where $T, p, v, h$ and $c_{v}$ are temperature, pressure, specific volume, specific enthalpy and specific heat capacity of the refrigerant inside the cylinder, while $M$ is the mass of refrigerant inside the cylinder, $q$ is the heat flow rate exchanged between refrigerant and the cylinder wall, $\mathrm{V}$ is the volume inside the cylinder, $\mathrm{m}$ is mass flow rate and $\tau$ is time. The subscripts $\mathrm{s}$, $\mathrm{d}$ and $\mathrm{l}$ refer to suction, discharge and leakage conditions, while $\mathrm{v}$ refers to the constant volume condition. Refrigerant to cylinder wall heat transfer has been computed by equation of Annand et al. 1963 [3] multiplied by a factor of three as suggested by Todescat et al. 1992 [2]:

$$
\begin{gathered}
q(\tau)=\alpha(\tau) \mathrm{A}(\tau)\left[\mathrm{T}_{c}-\mathrm{T}(\tau)\right] \\
\alpha(\tau)=3 \times 0.7[\lambda(\tau) / \mathrm{D}][\rho(\tau) \cup \mathrm{D} / \mu(\tau)]^{0.7}
\end{gathered}
$$

where $\alpha$ is the heat transfer coefficient, $\mathrm{A}$ is the heat transfer area, $\mathrm{D}$ is the cylinder diameter, $\mathrm{u}$ is the mean piston speed, $\lambda, \rho$ and $\mu$ are thermal conductivity, density and dynamic viscosity of the refrigerant. The subscript $c$ refers to cylinder wall. The refrigerant leakage mass flow rate has been computed by Jacobs 1976 [4] model

$$
\mathrm{m}_{\mathrm{l}}(\tau)=\rho(\tau) \pi \mathrm{Dh}^{3} \Delta \mathrm{p}(\tau) /[8 \mu(\tau) \mathrm{L}]
$$

where $\mathrm{h}$ is piston to cylinder radial clearance, $\mathrm{L}$ piston height and $\Delta \mathrm{p}$ pressure difference between cylinder and shell. The pressure behaviour during the compression cycle has been calculated using the following equation

$$
\mathrm{p}(\tau+\mathrm{d} \tau)=\mathrm{p}(\tau)[\mathrm{V}(\tau) / \mathrm{V}(\tau+\mathrm{d} \tau)]^{\mathrm{k}}+[(\mathrm{k}-1) / \mathrm{V}(\tau+\mathrm{d} \tau)] \mathrm{q}(\tau) \mathrm{d} \tau
$$

where $\mathrm{k}$ is the ratio between constant pressure and constant volume heat capacities of the refrigerant. This equation, suggested by Brock et al. 1980 [5] for compression of an ideal gas, considers separately the adiabatic pressure variation due to the piston motion, and the constant volume pressure variation due to heat transfer between the refrigerant and cylinder wall. The pressure behaviour during suction and discharge phases is computed by a proprietary model. The compression power during the cycle has been computed using the following equation

$$
W(\tau)=\left[p(\tau)-p_{s}\right] d V / d \tau
$$

where $\mathrm{p}_{\mathrm{s}}$ is the refrigerant pressure in the shell. The cylinder inside volume and the heat transfer area between refrigerant and cylinder wall during the compression cycle have been evaluated using the following equations:

$$
\begin{aligned}
& \mathrm{V}(\tau)=\mathrm{V}_{\mathrm{c}}+\left(\pi \mathrm{D}^{2} / 4\right)\left\{(\mathrm{C} / 2)[1+\cos \Phi(\tau)]+\mathrm{B}\left[1-\sqrt{ } 1-(\mathrm{C} / 2 \mathrm{~B})^{2} \sin ^{2} \Phi(\tau)\right]\right\} \\
& \mathrm{A}(\tau)=2\left(\pi \mathrm{D}^{2} / 4\right)+\pi \mathrm{D}\left\{(\mathrm{C} / 2)[1+\cos \Phi(\tau)]+\mathrm{B}\left[1-\sqrt{ } 1-(\mathrm{C} / 2 \mathrm{~B})^{2} \sin ^{2} \Phi(\tau)\right]\right\}
\end{aligned}
$$


where $V_{c}$ is the clearance volume, $C$ is the stroke of the piston, $B$ is the connecting rod lenght and $\Phi$ is the crank angle from the bottom dead centre. The refrigerant properties have been calculated using Refprop 4.1 .

The simulation computer code has an iterative structure. Input values are set for the boundary conditions (surroundings temperature, suction refrigerant temperature and pressure, discharge pressure) and the characteristic parameters of the hermetic unit (geometrical data, refrigerant, electric motor speed, electric and mechanical efficiencies). Guessed values are assumed for the refrigerant mass flow rate, refrigerant temperature at the inlet of the cylinder, for the temperature of the gas recirculated inside the shell and for the temperature of the cylinder. Then a thermal balance is established for each compressor component and the unsteady-state analysis of the compression cycle is carried out using a step by step procedure. In this way, the characteristic temperatures inside the compressor and along the refrigerant flow are computed together with refrigerant mass flow rate, heat flow rates and power input. The guessed temperatures and mass flow rate are compared against the calculated ones and further iterations are carried out until convergence is reached. The final output results include refrigerant mass flow rate and outlet temperature, temperatures inside the hermetic unit, heat flow rate, electric power input, and the behaviour of the characteristic parameters during the compression cycle.

\section{RESULTS AND COMPARISON WITH EXPERIMENTATION}

Experimental measurements have been carried out on an R600a reciprocating hermetic compressor with $8 \mathrm{~cm}^{3}$ swept volume and on an R134a reciprocating hermetic compressor with $6 \mathrm{~cm}^{3}$ swept volume. Each compressor has been inserted in a calorimetry rig for the measurement of the refrigerating capacity in accordance with ASHRAE Standard (temperature at outlet of the condenser and outlet of the evaporator $32^{\circ} \mathrm{C}$, condensation temperature $55^{\circ} \mathrm{C}$ ). During each test the following parameters have been measured: electric power input, refrigerating capacity, evaporation and condensation pressures, gas temperature at inlet and at outlet of the compressor, refrigerant temperature at outlet of the condenser and at outlet of the evaporator. The compressor is also equipped with several copper-constantan thermocouples to measure the temperatures of its components and of the refrigerant in different positions. Table 1 gives the comparison between the experimental data measured and the values calculated by the simulation program under the same operative conditions both for R134a and R600a hermetic compressors. Three different operative conditions are considered in accordance with ASHRAE standard: evaporation temperatures $-35^{\circ} \mathrm{C},-23.3^{\circ} \mathrm{C}$ and $-10^{\circ} \mathrm{C}$, respectively. There is a fair agreement between the calculated and experimental values.

Table 1. Comparison between experimental and calculated parameters

\begin{tabular}{|c|c|c|c|c|c|c|}
\hline 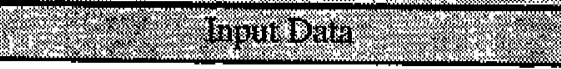 & 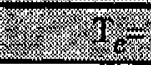 & 58 & 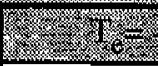 & $98(2)$ & 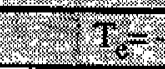 & $10 \% 6 \%$ \\
\hline Compressor inlet temperature $\left({ }^{\circ} \mathrm{C}\right)$ & & & & & 34 & \\
\hline Compressor suction pressure $(\mathrm{kPa})$ & & & & & 20 & 0.5 \\
\hline Compressor discharge pressure $(\mathrm{kPa})$ & & & & & & 86 \\
\hline 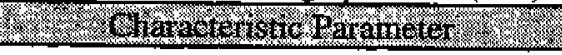 & 24 & (calc: & $2-7 \times 12=$ & $2.0 \times 18$ & $2 \times x_{2}{ }_{2}$ & $2 \times \mathrm{alc}$ \\
\hline Electric power input (W) & 92.5 & 100.7 & 137.7 & 141.8 & 204.7 & 203.5 \\
\hline Refrigerant mass flow rate $(\mathrm{kg} / \mathrm{h})$ & 1.316 & 1.122 & 3.016 & 2.779 & 6.009 & 5.601 \\
\hline Compressor outlet temperature $\left({ }^{\circ} \mathrm{C}\right)$ & 85.5 & 95.8 & 102.1 & 105.9 & 111.9 & 111.0 \\
\hline 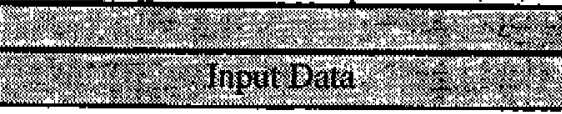 & 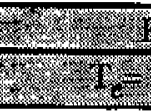 & 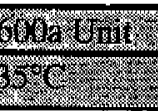 & 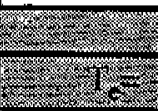 & 1878 & 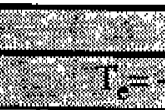 & $10 \%$ \\
\hline Compressor inlet temperature $\left({ }^{\circ} \mathrm{C}\right)$ & & & & & 33 & \\
\hline Compressor suction pressure $(\mathrm{kPa})$ & & & & & & \\
\hline Compressor discharge pressure $(\mathrm{kPa})$ & & & & & 7 & \\
\hline 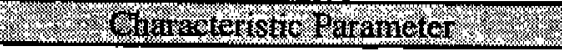 & $24 \mathrm{Exp}$ & $2016=$ & 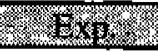 & (xac. & $28 \times \mathrm{p}$ & 2.9316 \\
\hline Electric power input (W) & 60.2 & 65.1 & 88.9 & 92.3 & 124.3 & 127.3 \\
\hline Refrigerant mass flow rate $(\mathrm{kg} / \mathrm{h})$ & 0.508 & 0.519 & 1.296 & 1.270 & 2.548 & 2.558 \\
\hline Compressor outlet temperature $\left({ }^{\circ} \mathrm{C}\right)$ & 75.3 & 77.3 & 86.4 & 85.2 & 91.9 & 87.1 \\
\hline
\end{tabular}




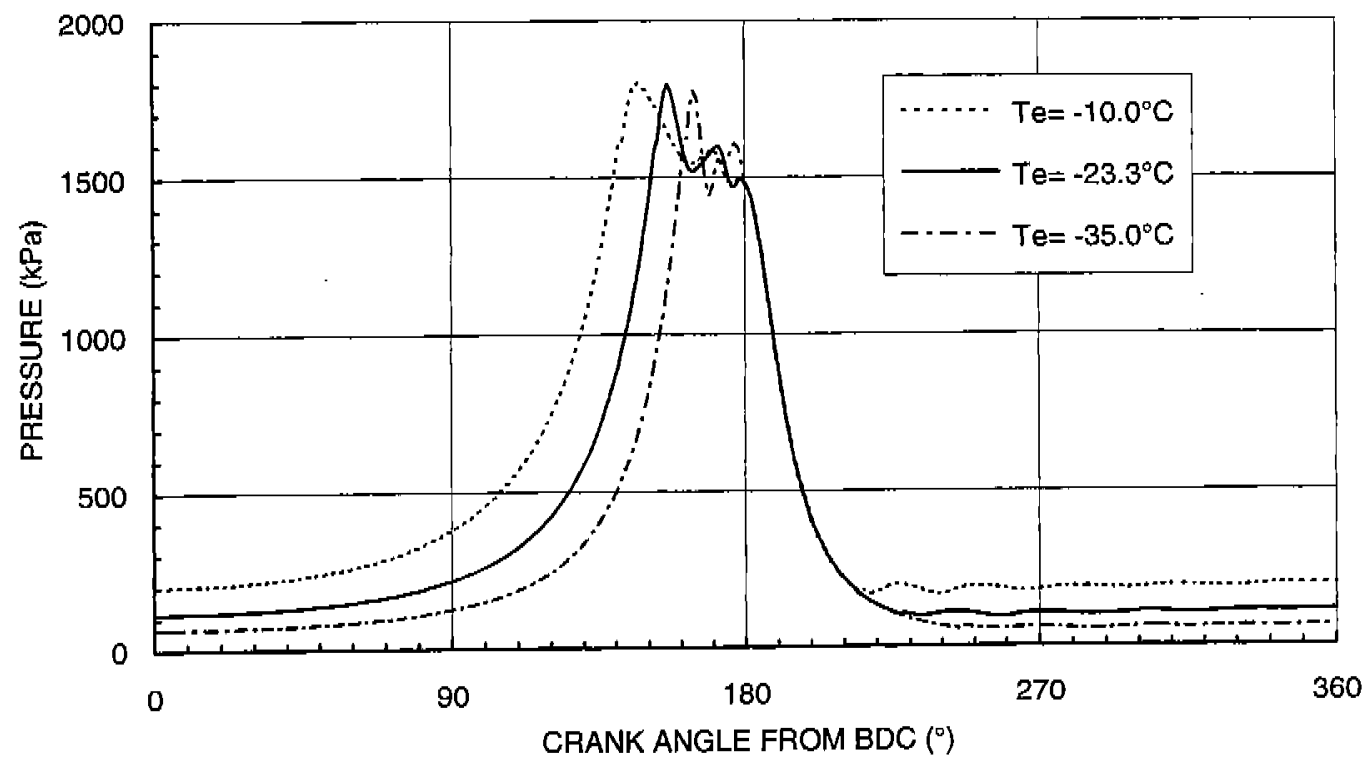

Figure 1. Pressure behaviour during the compression cycle: R134a unit.

The output of the simulation model also includes the behaviour of the characteristic parameters during the compression cycle: here, only the results relative to the R134a unit are reported. Figure 1 shows the pressure change for the R134a unit under the different operative conditions studied. It is possible to observe the compression phase, the discharge phase with the characteristic pressure fluctuation, the re-expansion of the refrigerant present in the clearance volume and finally the suction phase. Figure 2 shows the temperature behaviour: during the compression phase the refrigerant temperature increases until the opening of the discharge valve, when the temperature starts to decrease due to the heat exchange with the cylinder wall. The temperature decrease continues during the whole discharge and re-expansion phases until the opening of the suction valve, when the temperature again increases due to the mixing with the new entering refrigerant.

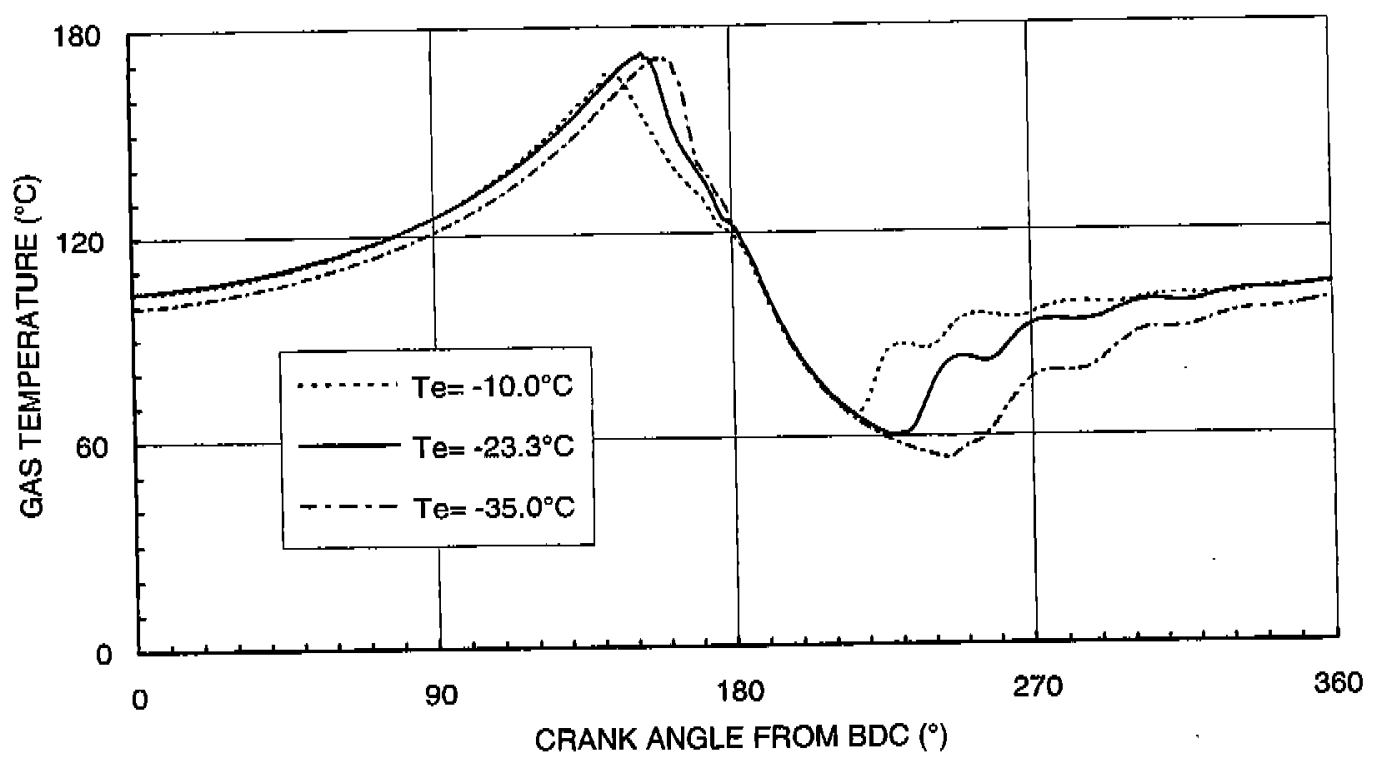

Figure 2. Temperature behaviour during the compression cycle: R134a unit. 


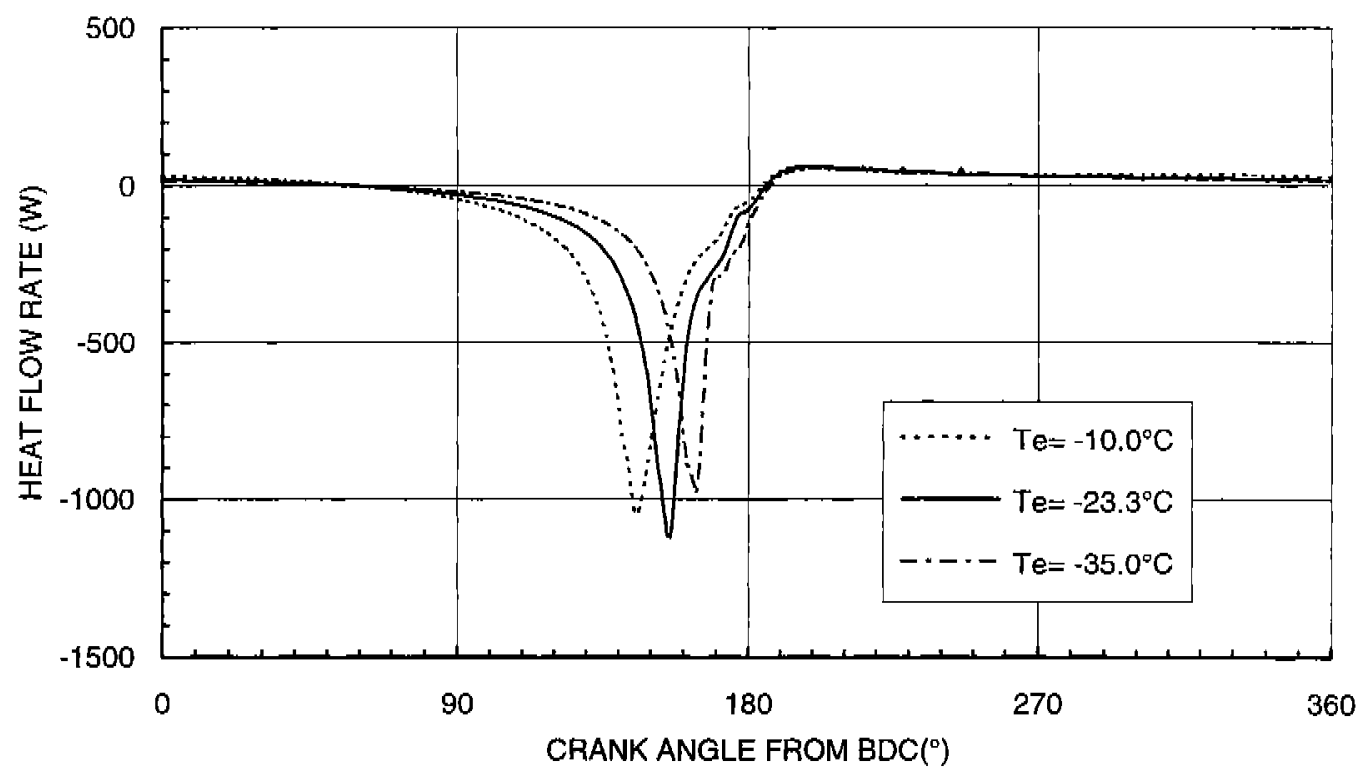

Figure 3. Heat transfer flow rate between refrigerant and cylinder wall during the compression cycle: R134a unit

Figures 3 and 4 show the change of heat and work flow rates for R134a unit in the different operative conditions studied. The heat transfer rate from the refrigerant to the cylinder wall enhances during the compression phase due to the increase in heat transfer coefficient and temperature difference between gas and wall. Then it rapidly decreases in the discharge and re-expansion phases until it reverses, from cylinder to gas, in the suction phase. The compression power augments, in absolute value, during the compression phase due to the increase of differential pressure on the piston and then it decreases in the discharge phase reaching zero at the top dead centre (no volume variation), and then becoming positive during the re-expansion phase. The subsequent suction phase involves a small power input.

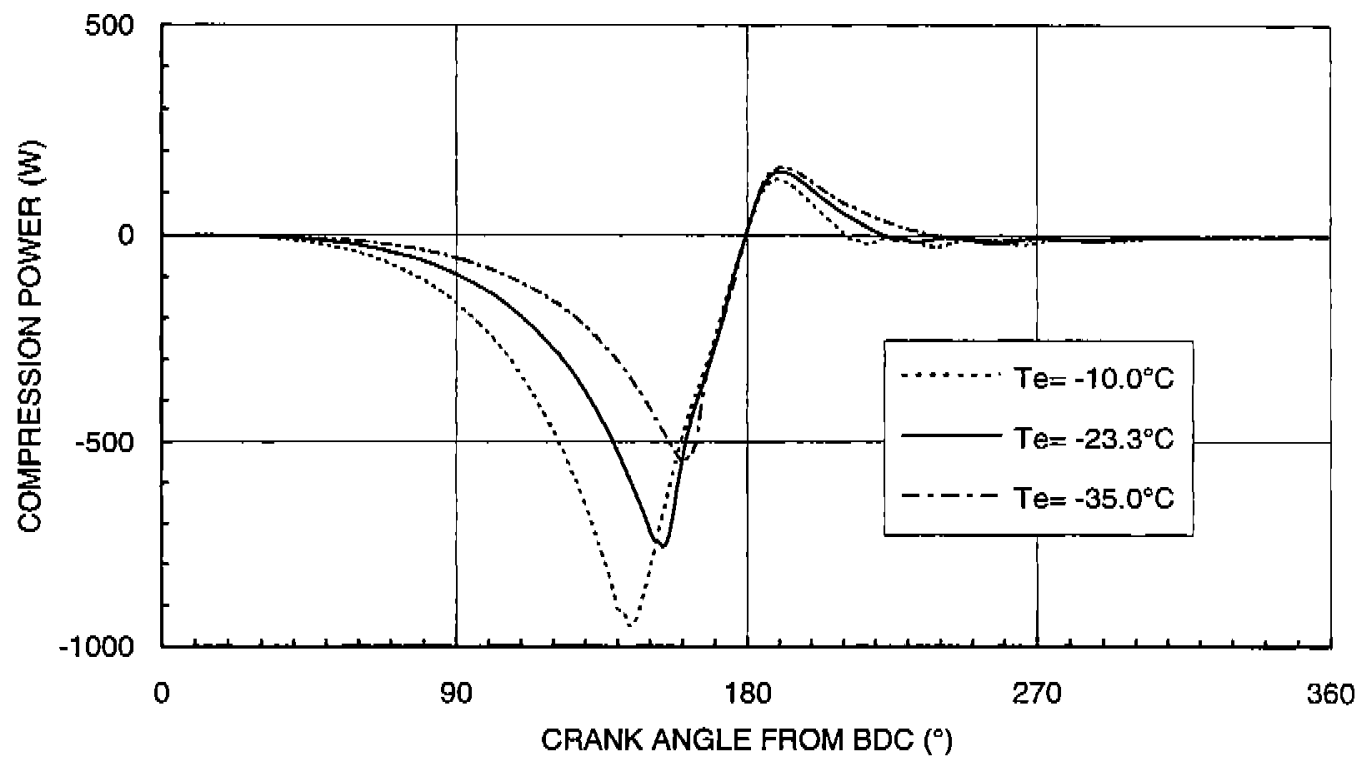

Figure 4. Work flow rate during the compression cycle: R134a unit 


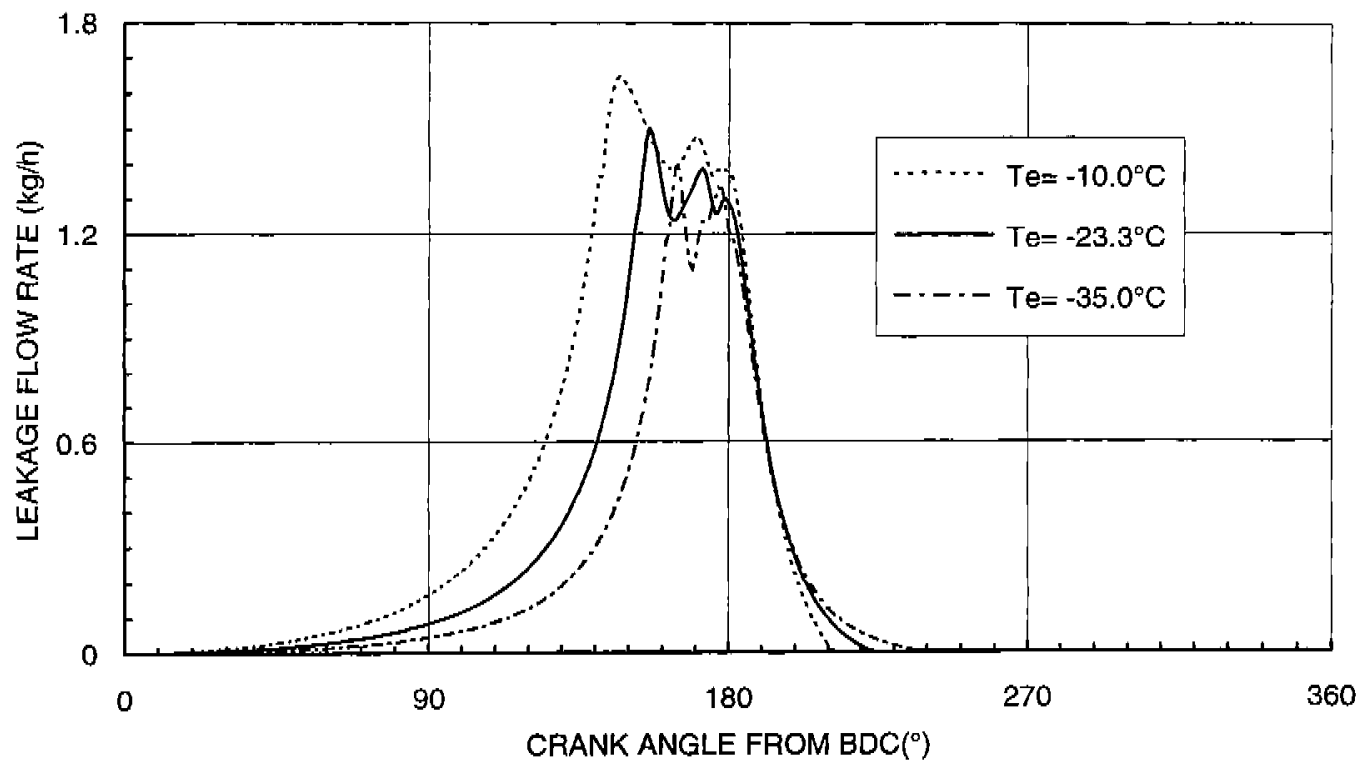

Figure 5. Flow rate leakage during the compression cycle: R134a unit.

Figure 5 shows the flow rate leakage from the cylinder to the shell volume during the compression cycle: this term is relevant only during the discharge phase due to the high differential pressure between cylinder and compressor shell. In the present analysis the flow rate leakage from shell to cylinder during the suction phase has been neglected.

\section{CONCLUSIONS}

A previous computer program for the steady-state thermal analysis of a small hermetic reciprocating compressor based on a politropic model, has been complemented with an unsteady-state analysis of the compression cycle. This new approach allows a direct computation of the heat and work flow rates exchanged together with the mass flow rate processed and also the change of the characteristic parameters during the compression cycle. It can be easily adapted to different operative fluids, different compressor geometries, and therefore it can be a useful tool for design and development purposes. In the present work, it has been validated against the experimental measurement carried out on an R134a and an R600a hermetic unit: a fair agreement has been found between predicted and measured performance.

\section{REFERENCES}

[1] Cavallini A., Doretti L., Longo G.A., Rossetto L., Bella B., Zannerio A. "Thermal Analysis of a Hermetic Reciprocating Compressor", Purdue International Compressor Engineering Conference, 1996, pp.535-540

[2] Todescat M.L., Fagotti F., Prata A.T., Ferreira R.T.S. "Thermal Energy Analysis in Reciprocating Hermetic Compressors", Purdue International Compressor Engineering Conference, 1992, pp.1419-1428

[3] Annand W.J.D. "Heat Transfer in the Cylinders of Reciprocating Internal Combustion Engines", Proc. of J. Mech. Engrs., 1963, vol. 117, pp.973-996.

[4] Jacobs J.J. "Analytical and Experimental Techniques for Evaluation of Compressor Performance Losses", Purdue International Compressor Technology Conference, 1976, pp.116-123.

[5] Brok S.W., Touber S., van der Meer J.S. "Modelling of Cylinder Heat Transfer - Large Effort, Little Effect?", Purdue International Compressor Technology Conference, 1980, pp.43-50 